\title{
Brief Report: Haloperidol Treatment of Trichotillomania in a Boy with Autism and Mental Retardation
}

\author{
M. Ghaziuddin, ${ }^{1}$ Luke Y. Tsai, and N. Ghaziuddin \\ University of Michigan, Ann Arbor
}

The DSM-III-R (American Psychological Association [APA], 1987) defines trichotillomania as an impulse control disorder characterized by the recurrent failure to resist impulses to pull out one's own hair. The diagnosis is not made if hair pulling is associated with inflammation or is in response to a delusion or hallucination. While its exact prevalence is not known (Krishnan, Davidson, \& Gujardo, 1985), it may be more common than generally believed. It is said to occur more frequently in women (DSM-III-R, APA, 1987) and in children (Muller \& Winkelmann, 1972). It is usually seen on the scalp, but can also involve the eyebrows, eyelashes (Mannino \& Delgado, 1969), and pubic hair (Fenichel, 1945). The hair loss is often characterized by short, broken strands appearing together with long, normal hairs in the affected area. Head banging, nail biting, scratching, and other forms of self-multilation may occur. Its etiology is not clear. Psychoanalysts have claimed that hair pulling may be perceived as a type of masturbation (Buxbaum, 1960), that it may occur when sexual conflicts are displaced on to hair, and that it may symbolize castration (Barahal, 1940). In up to a quarter of the cases, the onset may be associated with a history of stressful life events. No biological etiology has been proposed for this disorder due to lack of any systematic studies.

\footnotetext{
'Address all correspondence to M. Ghaziuddin, CAPH, Box 0390, University of Michigan Hospitals, 1500 E. Medical Center Drive, Ann Arbor, Michigan 48109-0390.
} 
A review of the literature suggests that in some patients, especially in children, hair pulling may present as a benign transitory symptom, while in others, it may coexist with major psychiatric disorders. Thus, it has been described in association with schizophrenia, obsessive-compulsive disorder, borderline personality disorder (Greenberg \& Sarner, 1965) and depression (Krishnan, Davidson, \& Miller, 1984; Naylor \& Grossman, 1991; Snyder, 1980). In addition to these disorders, it has been claimed that trichotillomania is particularly common in people with mental retardation. Thus, Kanner (1972) classified hair pulling under habit manipulations of the body and implied that if often occurred in children with mental retardation. The prevalence of trichotillomania in an institution for mentally retarded people has been estimated at about 1\% (Muller and Winkelmann, 1972). Most of the cases were found in the first two decades of life and many of the younger children also practiced thumb- or finger-sucking. However, despite this alleged association, an extensive 25-year computer-assisted search on trichotillomania in mental retardation, with or without autism, revealed only a few case reports. Thus, Hansen, Brask, Nielsen, Rasmussen, and Sillesan (1977) described the case of a 14-year-old severely mentally retarded autistic girl with a karyotype of 47 chromosomes who presented with aggressive outbursts, trichotillomania, and atypical minor epileptic fits. As the purpose of the article was to discuss the importance of parental counseling, trichotillomania was mentioned only as an incidental finding and therefore, no details about its presentation or treatment were given. Litt (1980) described the case of a 5-year-old mentally retarded boy who presented with trichotillomania. The onset was presumably associated with a stressful life event (threatened loss of and/or injury to his grandfather). The author speculated that, confronted with the threatened loss of the love object "and the symbolic castration of that object," the patient turned to "hair pulling for comfort." Treatment consisted of the mother clarifying the traumatic events to the child and helping him deal with his anxious and angry feelings. After a few weeks of therapy the symptoms disappeared and the patient continued to be well after 6 months.

Behavioral methods of treatment have also been used in the management of this problem, based on the assumption that, like most other forms of self-injurious behaviors, trichotillomania may also be conceptualized as a social behavior which is maintained in a social setting and is dependent on environmental cues. Matson, Stephans, and Smith (1978) used positive practice overcorrection procedure (Foxx \& Azrin, 1973) to treat compulsive hair pulling in an institutionalized 58-year-old profoundly mentally retarded woman. The treatment required the patient to brush her hair in an appropriate manner for 10 minutes contingent upon the occurrence of the target behavior. Barrett and Shapiro (1980) described the successful use of the same 
treatment procedure for reducing hair pulling in a 7-year-old severely mentally retarded girl. No mention was made if medication had been used in this or either of the previous two cases. To our knowledge, no reports have been published describing the pharmacological treatment of hair pulling in the mentally retarded or autistic population. In this case report, we describe the successful treatment of this disorder by haloperidol, in an 11-year-old boy with autism and mental retardation.

\section{CASE HISTORY}

$\mathrm{S}$ is an 11-year-old boy living with his parents. He is classified as severely mentally retarded. His last IQ assessment, done at the age of 9 years, was reported to be around 20 on the Stanford-Binet test.

He was referred to the University of Michigan Developmental Disorders Clinic for his severe self-injurious behavior consisting mainly of hair pulling. The other behaviors were scratching of the face and neck. The hair pulling was constant and persistent, occurring throughout the day, without any apparent precipitating or relieving factors. His head was covered with numerous bald patches covering at least $70 \%$ of the scalp. Hair on other parts of the body was not involved.

History revealed that in addition to hair pulling, he had the habit of spinning around and rocking himself for long periods of time. He showed no social smile or eye contact and did not seem to enjoy the company of children of his age. He had no verbal speech; his expressive speech consisted only of his tendency to repeat sounds, especially grunting sounds, over and over again. He seemed intolerant of natural light as he usually frowned and covered his eyes in its presence. Also, he disliked certain tastes and textures; for instance, he insisted on eating only soft foods and cereals.

He was born after a full-term normal delivery. However, when he was 11 days old, he was admitted to the hospital with a short history of drowsiness and irritability. On the basis of a vesical culture, he was diagnosed as suffering from herpes encephalitis. In addition, he developed bilateral herpetic uveitis and seizures, which were later managed by phenobarbital. Around 6 months of age, he was noted to be "socially indifferent." At that time, mother felt that he tended to ignore his surroundings, including his family members, and did not reach out to be picked up. He resisted being touched or held and sometimes showed no "startle response" to loud noises. He started walking around 12 months of age and for a long time, walked on his toes. At the same time, he was always "on the go" and rarely sat still. 
Onset of single words was reported around 18 months to 2 years of age. These included mom, dad, bye, and eat. However, according to the parents, word usage markedly diminished subsequently and the only current vocalizations were undifferentiated and consisted of neutral vowels. There was no imitation of adult verbalizations and communicative acts were minimal, consisting primarily of protesting.

Following a medical assessment at the age of 3 years, he was placed in a program for severely mentally retarded children. By this time, he had already started showing behavioral problems such as occasional temper tantrums, aggressive outbursts, and difficulty following directions. These problems gradually increased and when he was 7-8 years of age, additional services with a higher staff/patient ratio were recommended. Although the exact date of onset of hair pulling is not clear, according to the parents, it was after his ninth birthday. He was frequently seen picking at his head and pulling out tufts of hair. Various behavior modification techniques such as redirection and positive reinforcement were tried. Although the frequency of his maladaptive behaviors decreased when he was managed on a one-onone basis, it was generally felt that behavior modification had not been successful. At the same time, he was given a trial of Ritalin without success. Later he was placed on Mellaril (thioriadazine). At the time of the referral, he had been on Mellaril for about 18 months without much benefit. It was against this background that the referral was made for the purpose of trying a different medication. At interview, he was agitated and dishevelled. He hardly looked at the examiners and kept spinning around the room. He wore a head-cap which was meant to discourage him from pulling his hair; however, he kept taking it off continually to pull out his hair. There were scratch marks on his face and neck and numerous bald patches on the scalp.

Based on the history and the examination, a diagnosis of autistic disorder and severe mental retardation (DSM-III-R, APA, 1987) was made. He showed marked lack of awareness of the existence of others, showed no imitation, did not participate in social play and had a gross impairment in ability to make peer friendships. His expressive language was almost nonexistent with severely impaired nonverbal communication, absence of imaginative activity, and stereotyped movements. His hair pulling was felt to be consistent with an additional diagnosis of trichotillomania. He was started on oral haloperidol $1 \mathrm{mg}$ in the morning and $0.5 \mathrm{mg}$ at night; this was gradually increased to $1 \mathrm{mg}$ twice daily. A week after starting the medication, parents reported over the telephone that the hair pulling had stopped. "He has just stopped pulling his hair.... He is also a lot calmer..." We had arranged to see the patient after 2 weeks; however, as the parents could not keep the appointment, he was reviewed 5 weeks after starting the medication. During the interview, his improvement was confirmed. He looked calmer and brighter. Throughout the interview, he sat without pulling his hair and showed no other 
type of self-injurious behavior. His scalp also showed evidence of growing hair. At the 6 month follow-up he continued to be symptom-free so far as his hair pulling was concerned. Following this, in view of the continued clinical stability, dose reduction was attempted by decreasing his total haloperidol dose to $1.5 \mathrm{mg}$ daily. Within a week, parents reported renewed attempts at hair pulling, through without actually plucking the hair out from the roots. At parents' request, the dose was increased back to $2 \mathrm{mg}$ daily and again, within 5 to 7 days, parents reported that the patient had stopped trying to pull out his hair. $S$ has so far been followed for over 9 months and continues to be well. His hair pulling has completely disappeared, although his temper tantrums and occasional aggressive outbursts continue. His present medication is still haloperidol $2 \mathrm{mg}$ twice a day.

\section{DISCUSSION}

A variety of treatment approaches have been tried for the management of trichotillomania. Earlier reports stressed the value of psychodynamic psychotherapy. In pediatric and dermatologic settings where trichotillomania is said to be more often a benign self-limiting habit, behavior modification, counseling, or placebo-type interventions have been successful (Friman, Rostain, Parrish, \& Carey, 1990). Several pharmacologic agents have been tried. Trichotillomania associated with depression has been successfully treated with both tricyclic antidepressants (Snyder, 1980; Weller, Weller, \& Carr, 1989) and MAO inhibitors (Krishnan et al., 1984). Likewise, chlorpromazine has been used in the presence of schizophrenia (Childers, 1958).

Trichotillomania may be more closely related to obsessive-compulsive disorder than to other psychiatric illnesses because of its resemblance with other compulsive phenomena. In fact, some authors believe that trichotillomania falls within the category of obsessive-compulsive disorder (Philippopoulos, 1961). Support for this view comes from the successful use of clomipramine, a new tricyclic agent with selective antiobsessional properties (Swedo et al., 1989).

In the case described, there was insufficient evidence to suggest that the patient suffered from any of the DSM-III-R (APA, 1987) axis I disorders mentioned above. Instead, we conceptualized his hair pulling as a stereotypic behavior. Haloperidol was chosen because of the observation that major tranquilizers reduce stereotypies and other maladaptive behaviors in autism suggesting a possible role of dopaminergic mechanisms in this disorder (Mikkelsen, 1982). It is difficult to explain why haloperidol was successful when an earlier trial of thioridazine had failed despite the similarities in the actions of these two drugs; nor why haloperidol was effective in so short a time. The rapidity of response suggests that the decrease in hair 
pulling could not have been the result of the durg's antipsychotic action. Also, based on parental reports and clinical observation, it could not have resulted from its sedative effect.

Despite the success of haloperidol in this particular case, it must be conceded that no attempt was made to stop the medication to see if the symptoms would recur, although dose reduction did result in some reemergence of the symptoms. Thus, a strict ABAB design, in which treatment is alternated with an absence of treatment or placebo, was not employed mainly for ethical reasons. At the same time, any possible role of the environmental and social interactions, however small that might be, which may have contributed to the remission of symptoms, could not be ruled out. Despite these obvious limitations of the case report, we propose that when trichotillomania occurs in autism and mental retardation, and when it is not accompanied by depression or obsessive-compulsive symptoms, haloperidol may be a useful medication to try.

\section{REFERENCES}

American Psychiatric Association. (1987). Diagnostic and Statistical Manual of Mental Disorders (3rd ed., rev.). Washington, DC: Author.

Barahal, H. S. (1940). The psychopathology of hair pulling. Psychoanalytic Review, 27, 290-310.

Barrett, R. P., \& Shapiro, E. S. (1980). Treatment of stereotyped hair-pulling with overcorrection: A case study with long term follow-up. Journal of Experimental and Behavioral Psychiatry, 11, 317-320.

Buxbaum, E. (1960). Hair pulling and fetishism. Psychoanalytic Study of Child, 15, 243-260.

Childers, R. T. (1958). Report of two cases of trichotillomania of long standing duration and their response to chlorpromazine. Journal of Clinical and Experimental Psychopathology, 19, 141-144.

Fenichel, O. (1945). The psychoanalytic theory of neurosis. New York: W. W. Norton.

Roxx, R. M., \& Azrin, N. H. (1973). The elimination of autistic self-stimulatory behavior by overcorrection. Journal of Applied Behavioral Analysis, 6, 1-14.

Friman, P. C., Rostain, A., Parrish, J. M., \& Carey, W. B. (1990). Hair pulling (letter, comment). Journal of the American Academy of Child and Adolescent Psychiatry, 29, 489.

Greenberg, H. R., \& Sarner, C. A. (1965). Trichotillomania, symptom and syndrome. Archives of General Psychiatry, 12, 482-489.

Hansen, A., Brask, B. H., Nielsen, J., Rasmussen, K., \& Sillesan, I. (1977). A case report of an autistic girl with an extra bisatellited marker chromosome. Journal of Autism and Child Schizophrenia, 7, 263-267.

Kanner, L. (1972). Child psychiatry. Springfield, Ill: Charles C Thomas.

Krishnan, K. R. R., Davidson, J. R. T., \& Gujardo, C. (1985). Trichotillomania-A review. Comprehensive Psychiatry, 26, 123-128.

Krishnan, K. R. R., Davidson, J. R. T., \& Miller, R. D. (1984). MAO Inhibitors in the Treatment of Trichotillomania Associated with Depression. Journal of Clinical Psychiatry, 45, 267-268.

Litt, C. J. (1980). Trichotillomania in childhood: A case of successful short-term treatment. Journal of Pediatric Psychology, 5, 37-42.

Mannino, F. V., \& Delgado, R. A. (1969). Trichotillomania in children: A review. American Journal of Psychiatry, 126, 505-511. 
Matson, J. L., Stephans, R. M., \& Smith, C. (1978). Treatment of self-injurious behavior with overreaction. Journal of Mental Deficiency Research, 22, 175-178.

Mikkelson, E. (1982). Efficacy of neuroleptic medication in pervasive developmental disorders of childhood. Schizophrenia Bulletin, 8, 320-328.

Muller, S. A., \& Winkelmann, R. K. (1972). Trichotillomania-A clinicopathologic study of 24 cases. Archives of Dermatology, 105, 535-540.

Naylor, M., \& Grossman, M. (1991). Trichotillomania and depression (letter). Journal of the American Academy of Child and Adolescent Psychiatry, 30, 155-156.

Philippopoulous, G. S. (1961). A case of trichotillomania (hair pulling). Acta Psychotherapeutica et Psychosomatica, 9, 304-312.

Snyder, H. S. (1980). Trichotillomania treated with amitriptyline. Journal of Nervous and Mental Disease, 168, 505-507.

Swedo, S. E., Leonard, H. L., Rapaport, J. L., Lenane, M. C., Goldberger, E. L., \& Cheslow, D. L. (1989). A double-blind comparison of clomipramine and desipramine in the treatment of trichotillomania (hair pulling). New England Journal of Medicine, 321, 497-501.

Weller, E. B., Weller, R. A., \& Carr, S. (1989). Imipramine treatment of trichotillomania and co-existing depression in a seven year old. Journal of the American Academy of Child and Adolescent Psychiatry, 28, 952-953. 